\title{
ESTIMATIVA DO SALDO DE RADIAÇÃO NA SUPERFÍCIE UTILIZANDO IMAGENS DO SENSOR MODIS/AQUA E O ALGORITMO SEBAL: ESTUDO DE CASO PARA A BACIA DO RIO PARANAÍBA, BRASIL
}

\author{
Alécio Perini Martins 1 \\ Roberto Rosa
}

Resumo: O SEBAL (Surface Energy Balance Algorithms for Land) tem se mostrado ideal para a realização de estimativas de saldo de radiação, especialmente para regiões com grande extensão territorial. O estudo apresentado tem como objetivo demonstrar as etapas de implementação do SEBAL para estimativa de saldo de radiação utilizando imagens de sensoriamento remoto e técnicas de geoprocessamento. Foram utilizadas imagens do sensor MODIS/AQUA do ano de 2013 e ferramentas do software ArcGis $10.1 \circledR$ para implementar o modelo, que apontou valores médios de $865 \mathrm{~W} / \mathrm{m}^{2}$ para o saldo de radiação, com maiores valores registrados durante o período seco. A correlação mais forte foi identificada em relação aos valores de albedo, concluindo que mudanças no uso da terra podem alterar significativamente os valores de saldo de radiação e, por consequência, de fluxos de calor no solo e evapotranspiração.

Palavras-chave: Modelagem, sensoriamento remoto, saldo de radiação.

\section{SURFACE RADIATION BALANCE ESTIMATE USING IMAGES FROM MODIS/AQUA SENSOR AND THE SEBAL ALGORITHM: CASE STUDY FOR THE RIO PARANAÍBA RIVERBASIN, BRAZIL.}

\begin{abstract}
SEBAL (Surface Energy Balance Algorithms for Land) has proved itself ideal for accomplishing estimates of radiation balance, specially for regions with large territories. The study presented has as an objective to demonstrate the steps of implementation of SEBAL to estimate radiation balance using images of GIS and GIS techniques. We used images from MODIS/AQUA sensor from the year of 2013 and tools from ArcGis $10.1 \circledR$ software to implement the model, which pointed out average values of $865 \mathrm{~W} / \mathrm{m}^{2}$ to the radiation balance, with higher values registered during the drought period. The stronger correlation was identified in relation to the albedo values, concluding that changes in land use can change significantly the values of the radiation balance and, therefore, the heat fluxes in the soil and evapotranspiration.
\end{abstract}

Keywords: Modeling; GIS, Radiation Balance.

\footnotetext{
${ }^{1}$ Professor, Doutor. Universidade Federal de Goiás/Regional Jataí, Unidade Acadêmica Especial de Estudos Geográficos - Laboratório de Geoinformação. alecioperini@ufg.br

2 Professor, Doutor. Universidade Federal de Uberlândia, Instituto de Geografia - Laboratório de Geoprocessamento.rrosa.geo@gmail.com
} 


\section{INTRODUÇÃO}

Diversos estudos na área de meteorologia, climatologia e mudanças climáticas têm procurado avaliar as relações entre mudanças no uso da terra, desmatamento e alterações nos padrões de albedo, temperatura de superfície, saldo de radiação, entre outros, bem como na dinâmica pluviométrica.

Recentemente, foi veiculado um estudo da Agência Espacial Americana (NASA) que aponta o ano de 2014 como o mais quente desde quando essas informações começaram a ser registradas. No Brasil, dados climáticos apontam que as chuvas ficaram muito abaixo da média, o que fez com que reservatórios do centro-sul do país chegassem a níveis extremos, deixando milhões de pessoas sob risco de racionamento. Esses sinais também podem ser visualizados em imagens termais obtidas por sensoriamento remoto, que apontam temperaturas de superfície superiores a 45 graus em áreas urbanas e regiões agrícolas com solo descoberto.

Frente às intensas alterações na paisagem, em especial a partir do século $X X$, bem como o aperfeiçoamento de técnicas de estudo e modelos de previsão de cenários de mudanças ambientais, a geografia tem exercido papel importante por ser uma ciência que apresenta uma visão ampla dos fenômenos, permitindo que atividades de planejamento e gestão, bem como de mitigação de impactos, sejam mais eficientes, especialmente ao utilizar ferramentas de análise espacial como imagens de sensoriamento remoto e sistemas de informação geográficas.

A velocidade de evolução das geotecnologias exige um crescente investimento na área de Tecnologias da Informação, principalmente no que diz respeito à aquisição e adaptação de softwares, bem como imagens de satélite e instrumentos de monitoramento. Nesse sentido, a pesquisa aqui apresentada teve como objetivo avaliar a utilização de dados do sensor MODIS/AQUA para estimar o saldo de radiação na superfície utilizando o cálculo de balanço de radiação proposto no algoritmo SEBAL (Surface Energy Balance Algorithms for Land) desenvolvido por Bastiaanssen (1995). Para implementação do modelo, foi escolhida a bacia do Rio Paranaíba, que drena partes dos territórios dos estados de Minas Gerais, Goiás, Mato Grosso do Sul e Distrito Federal (Brasil) por apresentar diversidade de ambientes interessantes para aplicação do modelo, além de representar uma área de aproximadamente $230.000 \mathrm{Km}^{2}$, ideal para essas experimentações que apresentam maior margem de acerto para superfícies extensas.

O conhecimento dos valores do saldo de radiação é fundamental para mensurar a perda de água em superfícies vegetadas, sendo de grande importância para o planejamento de atividades agrícolas. De acordo com Nicácio (2008), esses valores podem ser obtidos de forma instrumental, a partir de radiômetros, ou de forma empírica, utilizando modelos matemáticos como é o caso do SEBAL.

As estimativas foram realizadas utilizando o algoritmo SEBAL a partir de princípios físicos envolvidos na reflexão, transmissão e absorção de energia pela superfície, necessitando de poucos dados coletados em campo e, portanto, permitindo o estudo de extensas áreas ou para regiões com poucos dados disponíveis ou de difícil acesso. O modelo se aplica tanto para imagens do sensor TM/Landsat quanto para imagens do sensor MODIS (TERRA ou AQUA), sendo essas últimas mais recomendadas para regiões extensas por cobrirem áreas de $10^{\circ}$ x $10^{\circ}$, aproximadamente.

Inicialmente, foram utilizadas imagens do sensor MODIS a bordo da plataforma TERRA, porém foram obtidos melhores resultados com imagens do sensor MODIS da plataforma AQUA, cujo horário de passagem sobre a região 
coincide com o período do dia no qual os processos mapeados são mais intensos (por volta de 14:30h).

Entre as dissertações de mestrado e teses de doutorado desenvolvidas no Brasil utilizando o algoritmo SEBAL, destacam-se os trabalhos de Giacomoni (2005) pela UFRGS, Bezerra (2006) pela UFCG, Nicácio (2008) pela UFRJ, Gomes (2009) pela UFCG, Leite (2011) pela UFU, Uda (2012) pela UFSC, entre outros. As principais publicações em periódicos concentram-se na Revista Brasileira de Meteorologia, Journal of Hidrology, Elsevier, Journal Hydrologic Engineering, além de anais de eventos como o Simpósio Brasileiro de Sensoriamento Remoto e do Congresso Brasileiro de Meteorologia. Percebe-se que a utilização desta metodologia em programas de pós-graduação em geografia no Brasil não é significativa se comparada à sua utilização nas áreas de meteorologia, recursos hídricos e até mesmo em engenharia civil. Existem também poucas publicações do tema em revistas específicas de Geografia e periódicos ligados a programas de pósgraduação em Geografia no Brasil.

\section{FUNDAMENTAÇÃO TEÓRICA E PROCEDIMENTOS METODOLÓGICOS}

O monitoramento de superfície, relacionado à observação continuada das condições do tempo vem, a cada dia, sendo substituído por dados obtidos por satélites, cada vez mais especializados na coleta de dados climáticos. Além de permitir uma cobertura maior, esses satélites possibilitam a obtenção de uma maior quantidade de dados em intervalos de tempo menores.

Basicamente, os sensores remotos trabalham com o balanço entre a principal fonte de energia que atinge a superfície terrestre - a radiação solar - e os padrões de reflectância dos diferentes objetos na superfície. De acordo com Ayoade (2010), o sol fornece $99.97 \%$ da energia que é utilizada no sistema terra-atmosfera, emitindo energia em ondas eletromagnéticas que se propagam à razão de $299.300 \mathrm{~km} / \mathrm{s}$.

Quando aquecida pela radiação solar, a superfície terrestre também se torna uma fonte de radiação de ondas longas ao refletir a energia recebida e emitir calor. "A maior parte da radiação emitida pela Terra está na faixa espectral infravermelha de $4 \mu \mathrm{m}$ até $100 \mu \mathrm{m}$ " (AYOADE, 2010, p.33).

Tendo em vista a curva de emissão do Sol, podemos considerar que, para comprimentos de onda entre $0,4 \mu \mathrm{m}$ e $2,5 \mu \mathrm{m}$, a energia utilizada para o Sensoriamento Remoto dos recursos terrestres é o fluxo solar refletido e, para comprimentos de onda maiores que $6 \mu \mathrm{m}$, a energia utilizada para o Sensoriamento Remoto dos recursos terrestres é o fluxo termal emitido pela superfície terrestre (NOVO, 2008, p.21)

Esses princípios envolvendo energia solar, energia terrestre e energia atmosférica compõem o balanço de radiação, entendido como a diferença entre a quantidade de radiação que é absorvida e emitida por uma superfície. Já o balanço de energia terrestre relaciona o fluxo de radiação líquida à transferência de calor latente e de calor sensível, entre outros. Esse balanço vai determinar, por exemplo, a quantidade de calor retida na atmosfera (temperatura do ar), a pressão atmosférica, a dinâmica das massas de ar, as precipitações, a evapotranspiração, entre outros elementos climatológicos que o avanço do sensoriamento remoto 
permite estudar com mais precisão e dinamicidade. O balanço de energia na terra é dado pela equação 1 (AYOADE, 2010, p.39)

$$
R=L E+H+G+\Delta f+P
$$

Onde $\mathrm{R}$ é o balanço de radiação ou radiação líquida, LE é o calor latente da evaporação, $\mathrm{H}$ é o calor sensível (todos medidos em $\mathrm{W} / \mathrm{m}^{2}$ ), $\Delta f$ é a advecção horizontal de valor pelas correntes (desprezível sobre superfícies continentais), G é o calor transferido para dentro ou para fora da armazenagem e P é a energia usada para a fotossíntese (cerca de $5 \%$ da radiação líquida).

Na meteorologia, os satélites são equipados com radiômetros infravermelhos que operam mesmo no período escuro da Terra, coletando dados meteorológicos e se comunicando com plataformas destinadas a registrar parâmetros como pressão atmosférica, temperatura e velocidade dos ventos na alta atmosfera, no mar e em superfície. O primeiro satélite colocado em órbita foi o Tiros-1 em 1960 e, a partir deste, outros sistemas foram lançados em órbita baixa ou geoestacionária (MOREIRA, 2011).

Moreira (2011) destaca que o uso dos satélites para pesquisa e monitoramento dos recursos naturais (satélites científicos) teve início na década de 1970, quando o ERTS-1 foi colocado em órbita, posteriormente batizado como Landsat. A partir daí vários outros sistemas foram colocados em órbita e grandes esforços e recursos financeiros têm sido aplicados no aprimoramento destas tecnologias visando um monitoramento mais preciso e com maior periodicidade do território. Ainda de acordo com Moreira (2011), os sistemas sensores podem ser agrupados de acordo com o objetivo de criação e aplicações, podendo ser empregados nas áreas militar, científica, meteorologia e telecomunicação.

Nas décadas de 1970 e 1980, com as intensas alterações ambientais e socioeconômicas na superfície do planeta, os debates sobre as questões ambientais e possíveis mudanças no clima estimularam a criação de um programa internacional chamado EOS (Earth Observing System) liderado pela NASA (National Aeronautics and Space Administration) para o estudo dos processos de mudanças globais. Iniciado na década de 1980, o EOS teve sua primeira plataforma lançada em 1999 (TERRA), com observações no período da manhã e com os seguintes sensores a bordo: CERES, MODIS, ASTER E MOPITT, com passagem pelo Equador às 10:30h da manhã e órbita descendente. A segunda plataforma do EOS recebeu o nome de AQUA, foi lançada em 2002 e tem abordo os sensores MODIS, AIRS, AMSU-A, HSB, AMSR-E e CERES. O AQUA cruza o Equador às 13:30h, com trajetória ascendente e tem por objetivo subsidiar a coleta de informações sobre o ciclo da água na Terra, além de fluxos de energia radiativa, cobertura vegetal e temperaturas do ar, da terra e da água (SOARES, BATISTA e SHIMABUKURO, 2007).

O sensor MODIS (Moderate Resolution Imaging Spectroradiometer) opera em 36 canais espectrais, com resolução espacial variando de 250 a 1.000 metros e com imagens disponibilizadas gratuitamente, tanto pelo INPE quanto pela NASA, em formato "hdf", facilmente convertido para "tif", em 12 bits, com diferentes aplicações terrestres (bandas 3, 4, 5, 6 e 7, além das bandas 20, 21, 22 e 23 que permitem o mapeamento da temperatura de superfície). A partir destas bandas, foram gerados produtos denominados MODLAND que permitem estudos aprofundados dos ecossistemas terrestres em escala média/pequena, divididos em 03 grupos, conforme Latorre, Shimabukuro e Anderson (2007, p.24): 
a) Produtos relacionados ao balanço de energia: MOD 09 (refletância de superfície); MOD 11 (Temperatura da superfície da Terra e Emissividade); MOD 43 (BRDF/Albedo); MOD 10 e 29 (Cobertura de neve e extensão de gelo na superfície do mar).

b) Produtos relacionados à vegetação: MOD 13 (Grades de índices de vegetação (máximo NDVI e MVI integrado); MOD 15 (índice de área foliar (LAI) e FPAR); MOD 17 (fotossíntese líquida e produtividade primária)

c) Produtos relacionados à cobertura terrestre: MOD 12 (cobertura da terra e mudança na cobertura da terra); MOD 14 (anomalias termais, fogo e queima de biomassa); MOD 44 (Conversão da cobertura vegetal).

Em especial, os produtos MOD09 (plataforma TERRA) e o MYD09 (plataforma AQUA) podem ser utilizados como dado de entrada para a obtenção de diversas informações, como albedo, índice de vegetação, fluxo de calor no solo, evapotranspiração e saldo de radiação, fundamentais à pesquisa proposta.

O produto MOD09 do MODIS é uma estimativa da refletância de superfície, e é computado a partir do nível $1 \mathrm{~A}$ nas bandas $1,2,3,4$, 5 , 6 e 7 com os comprimentos de onda centrados em 0,648 $\mu \mathrm{m}$, $0,858 \mu \mathrm{m}, 0,470 \mu \mathrm{m}, 0,555 \mu \mathrm{m}, 1,240 \mu \mathrm{m}, 1,640 \mu \mathrm{m}$ e 2,130 $\mu \mathrm{m}$, respectivamente. (LATORRE, SHIMABUKURO E ANDERSON, 2007, p. 24-25)

Destacam-se, ainda, os produtos MOD11 (plataforma TERRA) e MYD11 (plataforma AQUA), voltados especificamente para o mapeamento da temperatura superficial terrestre (TST) e emissividade, utilizados para estimar a TST em diferentes categorias de uso da terra e cobertura vegetal, visto sua importância para os cultivos agrícolas e para estudos que requerem essa informação e que encontram barreiras na ausência de estações climatológicas em grande parte do interior do Brasil.

De acordo com Trentin et al. (2011, p.7745), o produto MYD11

(...) utiliza dados dos níveis 2 e 3 com o algoritmo Land Surface Temperature (LST) e emissividade recuperados dos dados do AQUA/MODIS, com resoluções espaciais de $1 \mathrm{~km}$ e $5 \mathrm{~km}$ da superfície terrestre em condições atmosféricas adequadas (céu limpo). O algoritmo LST é utilizado para recompor pixels com emissividades conhecidas nas bandas 31 e 32.

Para entender como o sensoriamento remoto auxilia no monitoramento climático destes elementos em superfície, é preciso retomar as equações 1 e 2, que tratam do balanço de radiação e de energia terrestre, considerando a estimativa do saldo de radiação conforme exposto por Allen et al (2002) (equação 2).

$$
R_{n}=(1-\propto) R_{s} \downarrow+R_{L} \downarrow-R_{L} \uparrow-\left(1-\varepsilon_{0}\right) R_{L} \downarrow
$$

Onde $\mathrm{Rn}$ é o saldo de radiação à superfície $\left(\mathrm{W} \cdot \mathrm{m}^{-2}\right)$; Rs $\downarrow$ é a radiação de ondas curtas incidente à superfície $\left(\mathrm{W} \cdot \mathrm{m}^{-2}\right) ; \mathrm{R}_{\mathrm{L}} \downarrow$ é a radiação de onda longa incidente à superfície $\left(\mathrm{W} \cdot \mathrm{m}^{-2}\right) ; \mathrm{R}_{\mathrm{L}} \uparrow$ é a radiação de onda longa refletida e emitida pela 
superfície (W. $\left.\mathrm{m}^{-2}\right) ; \varepsilon_{0}$ é a emissividade da superfície $(-)$ e $\propto$ é o albedo da superfície (-)

A radiação de onda longa apresenta, na equação, duas componentes principais: a radiação de onda longa incidente à superfície, emitida pela atmosfera a partir da interação de seus componentes e pelas nuvens com a radiação solar; e a radiação de onda longa emitida pela superfície, que podem ser estimadas a partir da emissividade atmosférica, da emissividade da superfície e da temperatura de superfície. Já a radiação de onda curta incidente à superfície apresenta como principal fonte o sol e pode ser medida por piranômetros, embora possa ser estimada a partir de uma equação considerando o ângulo de incidência dos raios solares e a transmissividade atmosférica.

Considerando essas variações entre ondas curtas e longas incidentes e refletidas, é possível calcular o albedo da superfície, que é definido como a razão entre a radiação incidente sobre a superfície e a radiação refletida pela superfície, sendo aplicado apenas para a reflexão da radiação de onda curta (NICÁCIO, 2008)

O albedo varia conforme as características físico-químicas das superfícies e com o ângulo zenital. Um outro fator que pode promover variações do albedo são as atividades humanas, tais como desflorestamento, agricultura e urbanização. Em superfícies vegetadas, o albedo depende da textura do solo e das condições fisiológicas da copa da planta. Já em solo seco, o albedo é expressivamente maior que o observado em solo úmido, enquanto uma superfície lisa tem albedo maior que uma superfície rugosa (HARTMANN, 1994). Para Arya (2001), as variações inadvertidas ou intencionais do albedo local, regional ou global podem causar significativa variação no balanço de energia à superfície e, com isso, favorecem variações no micro ou macro-clima. Note-se que essa variabilidade do albedo afeta diretamente a temperatura do solo (NICÁCIO, 2008, p. 26)

O albedo pode ser mensurado, em superfície, quando é possível realizar medições de radiação de ondas curtas incidente e refletida, o que limita muito a análise temporal e espacial desta variável em grandes superfícies. Nesse sentido, o sensoriamento remoto tem se mostrado útil para estimativa do albedo, como as disponibilizadas pelos produtos MOD43 e MYD43 dos satélites Terra e Aqua (sensor MODIS) ou pelo processamento das bandas de reflectância dos produtos MOD09 e MYD09, conforme descritos no capítulo 02. Assim, gera-se um arquivo raster onde cada pixel traz informações diferentes sobre o albedo na área imageada, com variação ligada aos diferentes tipos de cobertura da superfície.

Ming e Liu (2000), em mapeamento realizado para o Estado de São Paulo a partir de imagens AVHRR/NOAA, destacaram que valores de albedo inferiores a 0,10 correspondem à corpos hídricos, entre 0,10 e 0,15 à vegetação intensa e de 0,15 a 0,25 à vegetação rasteira, pastagens e cultivos agrícolas. Valores entre 0,25 e 0,40 são típicos de áreas urbanas e com solo descoberto e regiões secas, enquanto que valores superiores a 0,40 indicam áreas com cobertura de nuvens.

Em Sistemas de Informações Geográficas, o saldo de radiação pode ser estimado pixel a pixel com a aplicação do modelo SEBAL (BASTIAANSSEN, 1995), desenvolvido especificamente para estudar os fluxos de calor no solo e estimar a evapotranspiração em regiões para as quais não se dispõe de dados meteorológicos 
consistentes. Assim, toda a análise é feita por dados multiespectrais de satélite, com poucas observações de campo e de superfície.

O SEBAL vem sendo utilizado por vários pesquisadores no mundo todo para diversos agrossistemas, destacando os estudos de Bastiaanssen (1995; 2000), Bastiaanssen et al (1998), Ahmad e Bastiaanssen (2003), Ayenew (2003), Hemakumara et al (2003), Tasumi et al (2005), Bezerra (2006) Kongo e Jewitt (2006), Kimura et al (2007), Mendonça (2007), Nicácio (2008), Mendonça et al (2009), Lima et al (2014), entre outros. Em grande maioria, essas pesquisas utilizaram como base imagens do sensor AVHRR-NOAA e da série de satélites Landsat, principalmente o sensor TM. (NICÁCIO, 2008)

A grande maioria das publicações em periódicos, dissertações de mestrado e teses de doutorado, no Brasil, que utilizam o SEBAL como metodologia apresentam, na maioria das vezes, as mesmas referências, remetendo às publicações de proposição e validação do modelo, especificamente as de Bastiaanssen (1995; 1998; 2000; 2002) e Allen et al (2002). Os principais grupos de pesquisa concentram-se nos estados da Paraíba (UFBP e UFCG) e Rio de Janeiro (UFRJ), além de publicações em menor volume nos estados do Paraná, Santa Catarina e Minas Gerais, sempre com aplicações voltadas para áreas de clima semi-árido e regiões de agricultura irrigada.

A vantagem do modelo SEBAL para estimativa de fluxos de calor na superfície e evapotranspiração real é que os componentes do cálculo do saldo de radiação podem ser mensurados separadamente, permitindo uma estimativa mais precisa. Outra vantagem é que ele necessita de poucas informações coletadas em campo, podendo ser aplicado em grandes extensões de terra. A escala dos resultados vai estar relacionada ao tamanho do pixel da imagem utilizada, sendo que estudos em áreas com usos da terra e coberturas vegetais muito heterogêneas requerem imagens com resoluções espaciais maiores. Conforme afirma Moreira et. al. (2010),

(...) os resultados dos estudos de validação são satisfatórios apesar de o algoritmo SEBAL ser fundamentado em formulações empíricas. BASTIAANSSEN (2000) comparou as estimativas do SEBAL com medições de campo e obteve um erro relativo na fração evaporativa de $20 \%, 10 \%$ e $1 \%$ nas escalas de $1 \mathrm{~km}, 5 \mathrm{~km}$ e $100 \mathrm{~km}$, respectivamente, concluindo que o SEBAL mostra melhores resultados em escala regional, como também em áreas com superfície heterogênea. (MOREIRA et. al., 2010, p. 1149)

No caso do mapeamento realizado para a Bacia do Rio Paranaíba, foi considerada uma escala de 1:2.000.000, que ficaria bem representada em uma impressão em papel A3. Para apresentação em A4 e no corpo do texto, essa escala torna-se menor, na casa de 1:3.000.000.

Para compreender os resultados gerados a partir da aplicação do algoritmo SEBAL é preciso analisar as diversas etapas em que ele se subdivide, sendo a primeira variável o balanço de energia na superfície que, conforme apresentado na figura 1, é calculado a partir da estimativa das radiações de onda curta e longa incidente e refletida pela superfície, além do albedo e da emissividade da superfície.

Como os produtos MODIS (TERRA OU AQUA) apresentam processamentos de correção atmosférica e informações de radiância e refletividade, utilizou-se de um procedimento descrito por Nicácio (2008) e Andrade et al (2010) para o produto MYD09GA (MODIS/AQUA) para calcular o albedo de superfície, que traz uma 
estimativa da reflectância espectral em cada banda, excluindo os efeitos da absorção e do espalhamento atmosférico (equação 3). Antes de executar a equação, é necessário multiplicar cada banda do MYD09GA por um fator de correção de 0,0001, necessário para adaptar a imagem que originalmente está em resolução de 12 bits para a metodologia proposta para imagens TM/Landsat, com resolução de 8 bits.

$$
\alpha=0,160 \rho 1+0,291 \rho 2+0,243 \rho 3+0,116 \rho 4+0,112 \rho 5+0,081 \rho 7-0,0015
$$

Onde $\rho 1, \rho 2 \ldots \rho 7$ correspondem às bandas de reflectância do produto MYD09GA.

Figura 1. Organograma do cálculo do saldo de radiação à superfície (Rn).

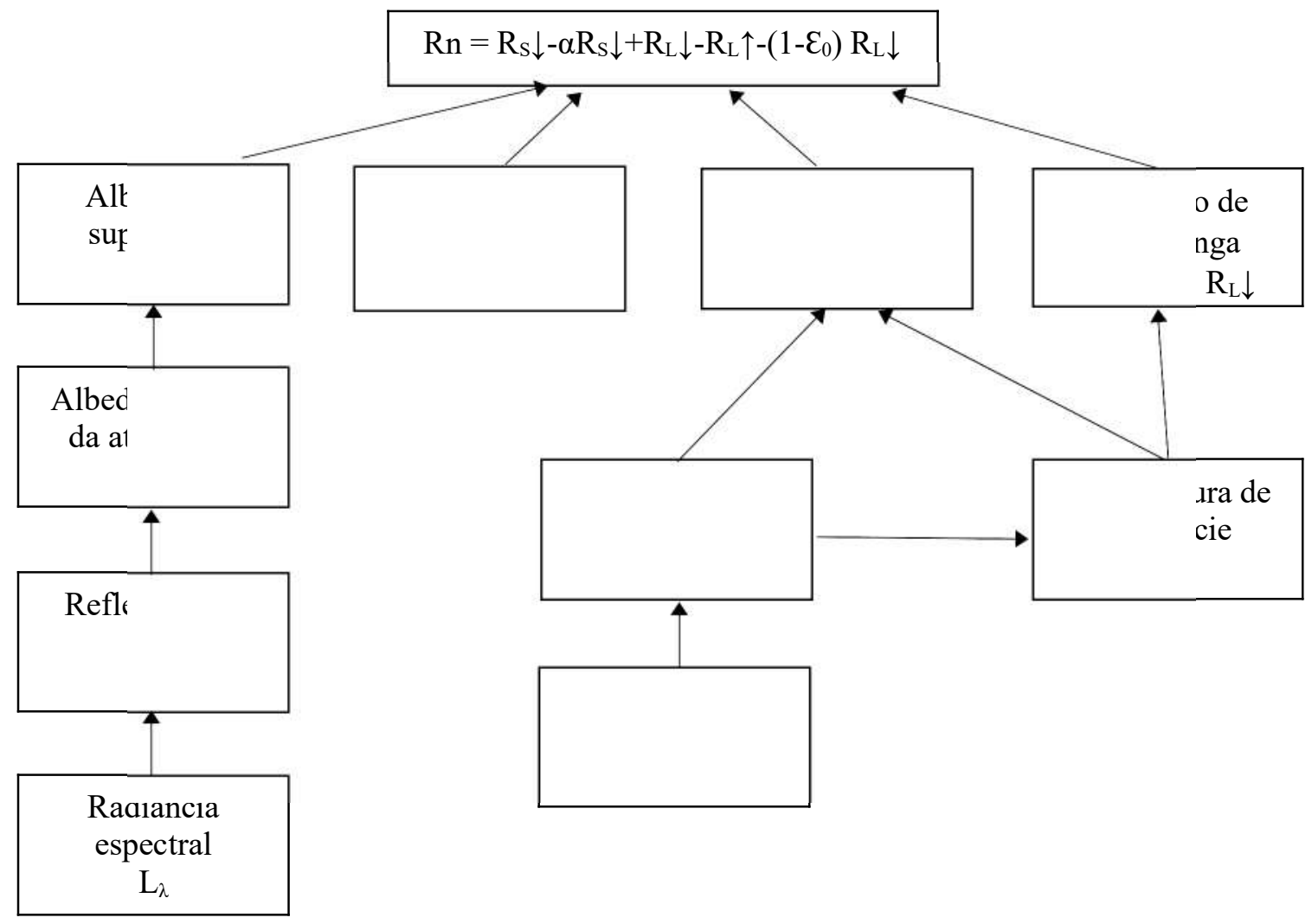

Adaptado de: Allen et al (2002)

A radiação de onda curta (ALLEN et al, 2002), entendida aqui como dados de entrada no sistema $(R s \downarrow)$, é o fluxo de radiação solar direta e difusa que realmente atinge a superfície da terra. Pode ser calculada conforme a equação $4\left(\mathrm{em} \mathrm{W} / \mathrm{m}^{2}\right)$, assumindo condições de céu limpo.

$$
R s \downarrow=G s c^{*} \cos \theta^{*} d r * \tau s w
$$

Onde Gsc corresponde a uma constante solar $\left(1367 \mathrm{~W} / \mathrm{m}^{2}\right)$; $\cos \theta$ é o cosseno do ângulo de incidência solar, fornecido nos metadados do produto MYD09GA; $d_{r}$ é o inverso do quadrado da distância entre Terra e Sol, calculado para o dia da imagem utilizada (calendário juliano); e $\tau s w$ é a transmissividade atmosférica que, por sua vez, pode ser obtida pela equação 5 (onde z corresponde à elevação em relação ao 
nível do mar). Neste caso, utilizamos a imagem SRTM/NASA (2000) com resolução espacial de 90 metros da área como dado de entrada para a variável $z$, calculando a transmissividade para cada pixel.

$$
\tau S w=0,75+2 * 10^{-5 * z}
$$

Para calcular a fração do balanço de energia correspondente à radiação de onda longa emitida pela superfície $(R L \uparrow)$, é necessário conhecer os valores de NDVI (Índice de Vegetação por Diferença Normalizada), de SAVI (Índice de Vegetação Ajustado ao Solo), de LAI (Índice de Área Foliar), emissividade de superfície e temperatura de superfície, conforme esquema da figura 01 (ALLEN et al, 2002). A radiação de onda longa emitida pela superfície $\left(\mathrm{W} / \mathrm{m}^{2}\right)$ corresponde ao fluxo de radiação térmica emitido pela superfície da Terra para a atmosfera, calculada conforme a equação 6 .

$$
R L \uparrow=\varepsilon 0 * \sigma * T S^{4}
$$

Para a obtenção da variável " $\varepsilon 0$ ", que corresponde à emissividade da superfície (equação 12), é necessário obter, previamente, o índice de área foliar (LAI), que por sua vez depende da determinação do SAVI e do NDVI. " $\sigma$ " corresponde à constante de Stefan-Boltzmann $\left(5,67 \times 10^{-8} \mathrm{~W} / \mathrm{m}^{2} / \mathrm{K}^{4}\right)$ e "Ts" corresponde à temperatura de superfície $(\mathrm{K})$.

O Índice de Vegetação por Diferença Normalizada (NDVI), obtido pela equação 7 (DEERING et al, 1975), corresponde ao índice utilizado para fazer análises sobre a cobertura vegetal em diferentes escalas, sendo gerado pela diferença entre a reflectância no canal do infravermelho próximo e a reflectância no canal do vermelho. O resultado da equação varia de $-1 \mathrm{a}+1 \mathrm{e}$, quanto maior o valor do índice, maior a presença de vegetação.

$$
N D V I=\frac{\rho i v p-\rho v}{(\rho i v p+\rho v)}
$$

Onde pivp é a reflectância na banda que capta respostas espectrais no infravermelho próximo, no caso do produto MYD09 a banda 2; e $\rho v$ é a reflectância na banda do vermelho, a banda 1 do produto MYD09.

No SEBAL, após o cálculo do NDVI, é necessário calcular o SAVI, que corresponde ao Índice de Vegetação Ajustado ao Solo que, segundo Allen et al (2002) é um índice que tem como objetivo subtrair os efeitos do fundo do solo na imagem do NDVI (equação 8), gerando um número geralmente menor do que o índice de vegetação.

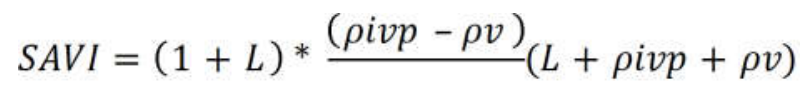

Nessa equação, $L$ corresponde a uma constante para o SAVI e varia de acordo com os solos da área. Segundo Allen et al (2002), se o $L$ for igual a 0 , o valor do SAVI será o valor do NDVI. Frequentemente, a literatura sugere o valor de 0,5 para a constante $\mathrm{L}$, em diferentes tipos de solo. $\mathrm{Na}$ proposição do modelo, Bastiaanssen (1995) utilizou um valor de 0,1 para L, que seria mais adequado para sua área de experimentação. 
Após o cálculo do SAVI, é possível conhecer o índice de área foliar da região estudada (LAI), variável necessária para se conhecer a emissividade da superfície utilizada no cálculo do saldo de radiação. De acordo com Allen et al (2002), o índice de área foliar é a razão da área total de todas as folhas de uma planta para a área do solo representado pela planta, sendo um indicador de biomassa e de resistência do dossel, podendo ser obtido conforme a equação 9 . O valor máximo para o LAl é de 6,0, correspondendo ao valor máximo de SAVI.

$$
L A I=-\frac{\operatorname{In}\left(\frac{0,69-S A V I}{0,59}\right)}{0,91}
$$

A emissividade de superfície $\left(\varepsilon_{0}\right)$ é a razão entre a energia térmica irradiada pela superfície e a energia térmica irradiada por um corpo negro à mesma temperatura (equação 10). Allen et al (2002), destacam que existem dois cálculos para a emissividade: a $\varepsilon_{\mathrm{NB}}$, utilizada para calcular a emissão termal para a banda 6 do sensor TM/Landsat; e a $\varepsilon_{0}$, utilizada nesse estudo, considerando a adoção de imagens MODIS/AQUA, necessária para calcular o total de radiação de onda longa emitida pela superfície. Nessa relação, quando o Índice de Área Foliar for maior ou igual a 3, a emissividade será igual a 0,98 (ALLEN et al, 2002, p.20). No caso da área de estudo, onde o LAI médio não ultrapassa 1,8 é necessário utilizar a equação para estimar a emissividade média.

$$
\varepsilon 0=0,95+0,01 L A I
$$

A última variável necessária para o cálculo da radiação de onda longa emitida pela superfície corresponde à temperatura de superfície $(K)$, que pode ser obtida com o uso do produto MYD11 do MODIS/AQUA. Os dados foram convertidos para graus de temperatura utilizando a ferramenta Raster Calculator do ArcGis10.1® por matemática de bandas aplicando um fator de multiplicação igual a 0,02 (ARRAES, LAMPARELLI e ROCHA, 2011) e, posteriormente, subtraiu-se o valor de 273,15 para converter as temperaturas de graus Kelvin para graus Celsius. É importante ressaltar que deve ser usada uma imagem do mesmo dia e horário das imagens utilizadas no balanço de radiação.

O último componente da fórmula para obtenção do saldo de radiação à superfície corresponde à radiação de onda longa incidente $(R L \downarrow)$, calculada pela equação 11, que é o fluxo de radiação para baixo a partir da atmosfera. O cálculo é feito utilizando a constante de Stefan-Boltzmann $(\sigma)$, a emissividade da atmosfera ( $\varepsilon a)$ e a temperatura de superfície (Ta).

$$
R L \downarrow=\varepsilon a^{*} \sigma^{*} T a^{4}
$$

A emissividade atmosférica pode ser calculada a partir do perfil logarítmico da transmissividade atmosférica (equação 12), conforme Allen et al (2002).

$$
\varepsilon a=0,85 *(-\operatorname{In} \tau s w)^{0,09}
$$

Para a aplicação do modelo, bem como o processamento das imagens e geração dos mapas temáticos, foi utilizado o software ArcGis $10.1 \circledast$ licenciado para o Laboratório de Geoinformação da Universidade Federal de Goiás/Regional Jataí, 
especificamente com as extensões 3D Analyst, Geoestatistical Analyst Tools e Spatial Analyst Tools.

Inicialmente, foram selecionadas imagens diárias para todos os meses de 2013 (pelo menos 01 imagem por mês com menor cobertura de nuvens), utilizando imagens dos dias 31 de julho (dia juliano 212) e 02 de agosto (dia juliano 214) para calibração do modelo (menor cobertura de nuvens), conforme o quadro 1 . As imagens foram adicionadas à tela de trabalho do ArcGis $10.1 \circledR$, onde os valores dos pixels foram multiplicados por um fator de escala de 0,0001 (ajuste dos números digitais dos pixels). Após a conversão, foi calculado o albedo de superfície utilizando a ferramenta "Raster calculator", onde criou-se uma equação com matemática de bandas. A mesma ferramenta foi utilizada para o cálculo do NDVI, SAVI e LAI, nesse caso, utilizando apenas as bandas 1 e 2 do MYD09GA.

Quadro 1. Imagens MODIS/AQUA selecionadas para aplicação do modelo SEBAL na bacia do Rio Paranaíba.

\begin{tabular}{|c|c|c|c|}
\hline Dia juliano & Dia gregoriano & Tiles & Condições do tempo \\
\hline 018 & 18 de janeiro de 2013 & $\begin{array}{c}\text { H12V10, H13V10, } \\
\text { H13V11 }\end{array}$ & $\begin{array}{c}\text { Céu nublado, registro de } \\
\text { chuvas em algumas regiões; } \\
\text { ventos fracos }\end{array}$ \\
\hline 045 & $\begin{array}{c}26 \text { de fevereiro de } \\
2013\end{array}$ & $\begin{array}{c}\mathrm{H} 12 \mathrm{~V} 10, \mathrm{H} 13 \mathrm{~V} 10, \\
\mathrm{H} 13 \mathrm{~V} 11\end{array}$ & $\begin{array}{l}\text { Céu parcialmente nublado, } \\
\text { registro de chuvas em } \\
\text { algumas regiões; ventos } \\
\text { fracos }\end{array}$ \\
\hline 073 & 12 de março de 2013 & $\begin{array}{c}\mathrm{H} 12 \mathrm{~V} 10, \mathrm{H} 13 \mathrm{~V} 10 \\
\mathrm{H} 13 \mathrm{~V} 11\end{array}$ & $\begin{array}{c}\text { Céu parcialmente nublado, } \\
\text { registro de chuvas em } \\
\text { algumas regiões; ventos } \\
\text { moderados }\end{array}$ \\
\hline 107 & 17 de abril de 2013 & $\begin{array}{c}\mathrm{H} 12 \mathrm{~V} 10, \mathrm{H} 13 \mathrm{~V} 10 \\
\mathrm{H} 13 \mathrm{~V} 11\end{array}$ & $\begin{array}{l}\text { Céu parcialmente nublado, } \\
\text { sem registro de chuvas; } \\
\text { ventos moderados }\end{array}$ \\
\hline 123 & 03 de maio de 2013 & $\begin{array}{c}\mathrm{H} 12 \mathrm{~V} 10, \mathrm{H} 13 \mathrm{~V} 10 \\
\mathrm{H} 13 \mathrm{~V} 11\end{array}$ & $\begin{array}{l}\text { Céu parcialmente nublado, } \\
\text { sem registro de chuvas; } \\
\text { ventos moderados }\end{array}$ \\
\hline 164 & 13 de junho de 2013 & $\begin{array}{c}\text { H12V10, H13V10, } \\
\text { H13V11 }\end{array}$ & $\begin{array}{l}\text { Poucas nuvens, sem registro } \\
\text { de chuvas; ventos moderados }\end{array}$ \\
\hline 212 & 31 de julho de 2013 & $\begin{array}{c}\text { H12V10, H13V10, } \\
\text { H13V11 }\end{array}$ & $\begin{array}{l}0 \% \text { de cobertura de nuvens, } \\
\text { período de estiagem superior } \\
\text { a } 30 \text { dias na região; ventos } \\
\text { moderados, com rajadas. }\end{array}$ \\
\hline 214 & 02 de agosto de 2013 & $\begin{array}{c}\mathrm{H} 12 \mathrm{~V} 10, \mathrm{H} 13 \mathrm{~V} 10, \\
\mathrm{H} 13 \mathrm{~V} 11\end{array}$ & $\begin{array}{l}0 \% \text { de cobertura de nuvens, } \\
\text { período de estiagem superior } \\
\text { a } 30 \text { dias na região; ventos } \\
\text { moderados, com rajadas. }\end{array}$ \\
\hline 269 & $\begin{array}{l}26 \text { de setembro de } \\
2013\end{array}$ & $\begin{array}{c}\mathrm{H} 12 \mathrm{~V} 10, \mathrm{H} 13 \mathrm{~V} 10 \\
\mathrm{H} 13 \mathrm{~V} 11\end{array}$ & $\begin{array}{c}\text { Poucas nuvens, sem registro } \\
\text { de chuvas; ventos moderados, } \\
\text { com rajadas. }\end{array}$ \\
\hline 283 & 10 de outubro de 2013 & $\begin{array}{c}\text { H12V10, H13V10, } \\
\text { H13V11 }\end{array}$ & $\begin{array}{c}\text { Céu parcialmente nublado, } \\
\text { sem registro de chuvas; } \\
\text { ventos moderados }\end{array}$ \\
\hline 331 & $\begin{array}{l}27 \text { de novembro de } \\
2013\end{array}$ & $\begin{array}{c}\text { H12V10, H13V10, } \\
\text { H13V11 }\end{array}$ & $\begin{array}{c}\text { Céu parcialmente nublado, } \\
\text { registro de chuvas em } \\
\text { algumas regiões; ventos } \\
\text { fracos } \\
\end{array}$ \\
\hline 338 & $\begin{array}{l}04 \text { de dezembro de } \\
2013\end{array}$ & $\begin{array}{c}\mathrm{H} 12 \mathrm{~V} 10, \mathrm{H} 13 \mathrm{~V} 10, \\
\mathrm{H} 13 \mathrm{~V} 11\end{array}$ & $\begin{array}{c}\text { Céu nublado, registro de } \\
\text { chuvas em algumas regiões; } \\
\text { ventos fracos }\end{array}$ \\
\hline
\end{tabular}

Fonte: NASA, 2014; BDMEP/INMET, 2014. 
Para o cálculo da temperatura de superfície, em graus Kelvin, utilizou-se o produto MYD11A1, multiplicando por um fator de escala de 0,02 para ajustar os valores dos números digitais. Para transformar os dados de temperatura em graus Celsius, padrão utilizado no Brasil, subtrai-se o valor de 273,15 de cada pixel utilizando a ferramenta Raster Calculator.

Após a geração das imagens classificadas, passou-se ao processo de reclassificação pela ferramenta reclassify, também da extensão Spatial Analyst Tools adotando classes com intervalos definidos manualmente a partir da amplitude apresentada, de forma que as informações ficassem bem representadas e permitissem comparações espaciais e temporais. Não foi definida uma quantidade de classes padrão, pois os dados apresentam amplitudes muito diferentes, podendo ser incorretamente representados caso fossem fixados valores padrão.

O mapa de uso da terra e cobertura vegetal foi elaborado para a imagem de abril de 2013 (MYD09A1 em composição de 08 dias, sem cobertura de nuvens) a partir das bandas 1, 2 e 7 em composição 7R2G1B (os resultados também são satisfatórios com o uso da banda 5 no lugar da banda 7). As imagens, já georeferenciadas, foram convertidas em formato ",tif" e resolução de 8 bits e posteriormente classificada, inicialmente, de forma não-supervisionada pela ferramenta "multivariate-isocluster" do Spatial Analyst Tools (segmentação), com detalhamento de 5 níveis de cinza para áreas de 3 pixels, com 60 classes que posteriormente foram reclassificadas em 06: corpos d'água, pastagens, área urbana, agricultura/silvicultura, solo descoberto, cerrado e floresta (vegetação natural/área de preservação) em processo de reclassificação visual. Posteriormente, as áreas de agricultura e solo descoberto foram agrupadas, visto que ambas representam áreas destinadas às práticas agrícolas.

Para a classificação, foi utilizado o método de máxima verossimilhança (ferramenta multivariate - maximum likelihood classification do Spatial Analyst Tools), atribuindo-se pesos iguais para as classes e com margem de acerto de $95 \%$. Não foi possível, pela resolução espacial das imagens utilizadas, delimitar áreas de agricultura irrigada e silvicultura, sendo todas agrupadas com as áreas de produção agrícola. Durante a calibração e teste do modelo, essas áreas foram visualizadas no Google Earth, auxiliando no processo de reclassificação e correção. Além do mapa elaborado a partir das mesmas imagens utilizadas para estimativa de evapotranspiração, foram utilizados o mapa de uso disponibilizado no Plano de Recursos Hídricos do Rio Paranaíba (ANA, 2013) e o mapa elaborado por ROSA e SANO (2014) com imagens TM/Landsat de 2010 para comparação dos resultados.

Apesar de o software utilizado na pesquisa necessitar de pagamento de licenças de uso, o processamento do modelo SEBAL pode ser realizado em softwares de download livre, como o SPRING e o Quantum GIS, embora esses softwares exijam uma habilidade maior do pesquisador para compor as programações com as equações do algoritmo.

\section{RESULTADOS E DISCUSSÃO}

A área escolhida para as experimentações da pesquisa é representada pela Bacia Hidrográfica do Rio Paranaíba (Mapa 1), um dos principais afluentes da Bacia do Rio Paraná, com área aproximada de 230.000 km². 
A bacia do rio Paranaíba é a segunda maior unidade da Região Hidrográfica do Paraná, ocupando $25,4 \%$ de sua área (...). Posicionada na região central do Brasil, ocupa cerca de 2,6\% do território nacional e inclui os estados de Goiás (63,3\%), Mato Grosso do Sul $(3,4 \%)$ e Minas Gerais $(31,7 \%)$, além do Distrito Federal $(1,6 \%)$. A bacia possui 197 municípios, além do Distrito Federal. Destes, 28 sedes municipais se encontram fora dos limites da bacia (ANA, 2013)

Rosa e Sano (2014) em mapeamento de uso da terra e cobertura vegetal elaborado a partir de imagens do sensor TM/Landsat do ano de 2010 (resolução de 30 metros), apontam que $68 \%$ da área encontra-se ocupada por atividades agropecuárias, sendo $27 \%$ para agricultura (incluindo agricultura irrigada) e $41 \%$ por pecuária (corte e leite). Esses dados demonstram o grau de ocupação das terras, bem como a vocação regional para atividades que vêm transforando os cenários econômico e ambiental na região nos últimos 40 anos.

Mapa 1. Localização da área de estudo.

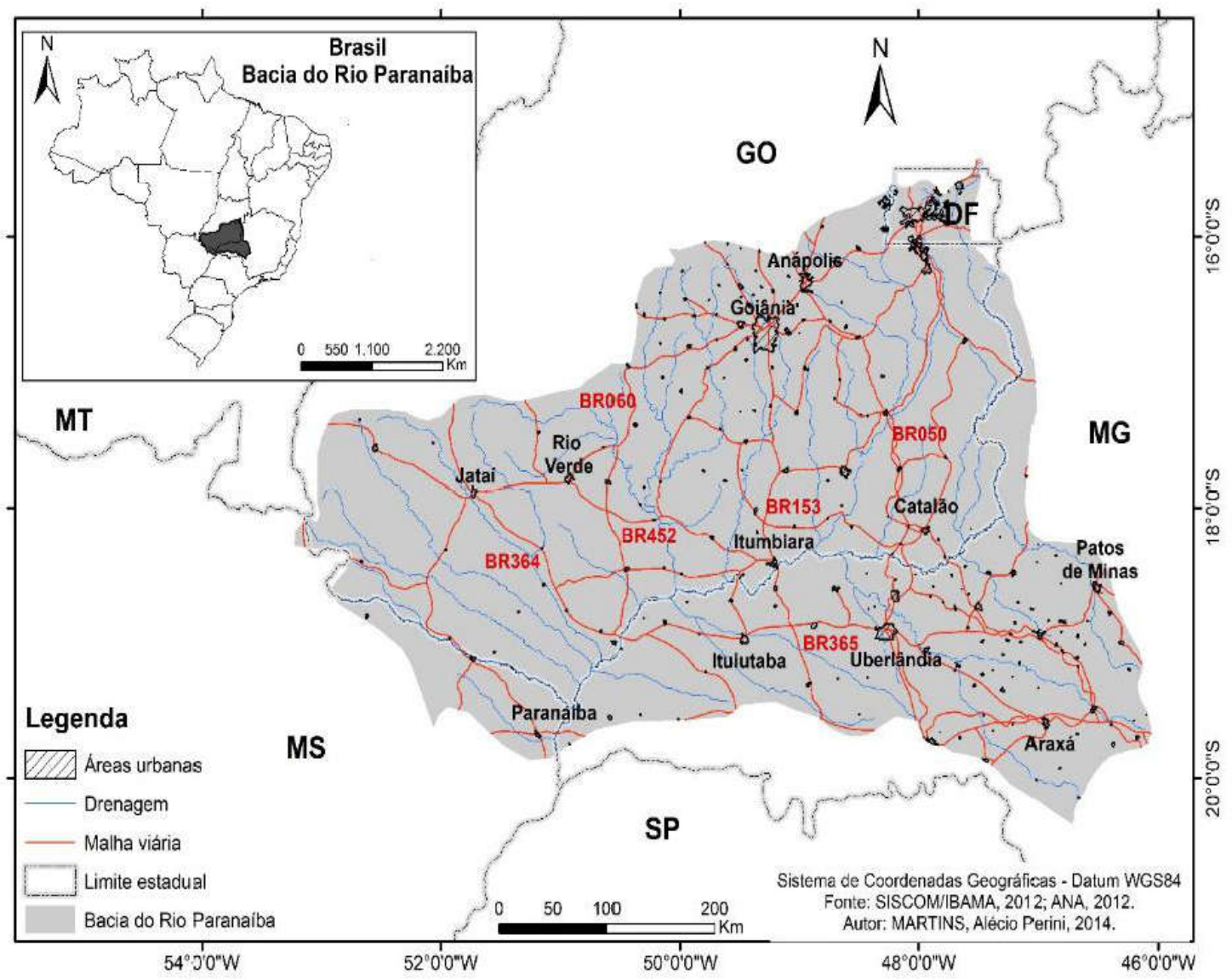

Fonte: Agência Nacional de Águas. 2012.

Autor: MARTINS, Alécio Perini, 2014.

No mapeamento de uso da terra e cobertura vegetal elaborado a partir de imagens do sensor MODIS/AQUA (resolução de 250 metros), para o mesmo período da estimativa do saldo de radiação realizado neste trabalho (ano de 2013), foi identificada uma área de $31 \%$ ocupada com agricultura e $40 \%$ com pastagem, correspondendo a $71 \%$ da área de estudo. As áreas com vegetação natural, que 
incluem formações florestais e diversas fitofisionomias de cerrado, estão restritas a $27 \%$ da área, com tendência a diminuir nos próximos anos.

No mapa 2 é possível observar que as atividades agrícolas estão concentradas na porção mineira da bacia do Rio Paranaíba e em regiões goianas próximas aos municípios de Jataí, Rio Verde, Itumbiara, Catalão, Cristalina e Morrinhos. As áreas de pastagem, que representam a forma inicial de ocupação e "abertura econômica" da região apresentam-se bem distribuídas pelo território, enquanto áreas de vegetação natural encontram-se restritas em áreas de proteção ambiental, como no Parque Nacional das Emas (extremo oeste da bacia), o Parque Nacional de Brasília (Distrito Federal), o Parque Nacional da Serra da Canastra (extremo sudeste da bacia, em Minas Gerais) e regiões de difícil ocupação agropecuária devido às características do meio físico, declividade, etc.

Mapa 2. Uso da Terra e Cobertura Vegetal na Bacia do Rio Paranaíba - 2013.

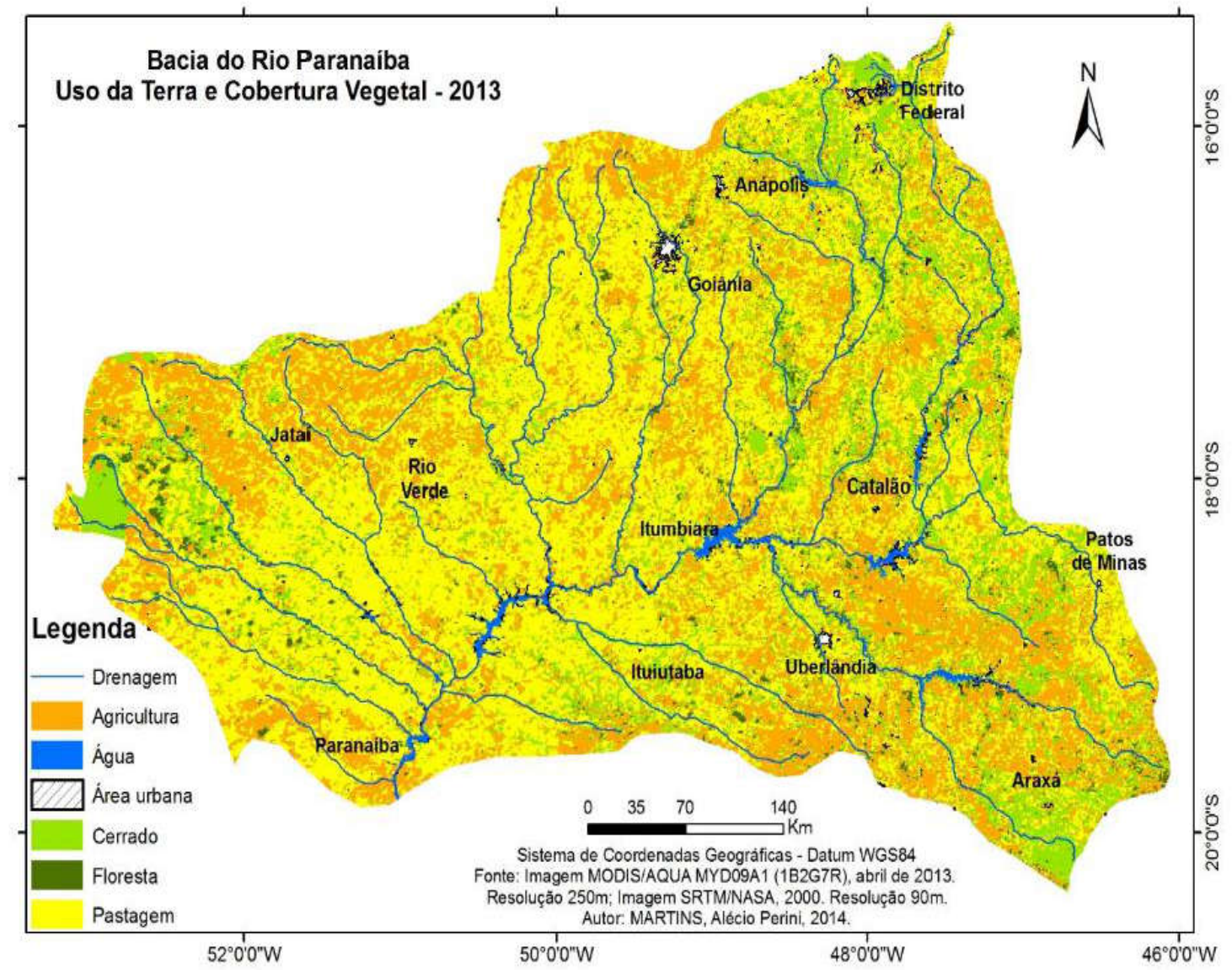

Fonte: Imagem MODIS/AQUA, produto MYD09GA, 2013

Autor: MARTINS, Alécio Perini, 2014.

A partir dos valores de albedo, temperatura de superfície, NDVI, SAVI, índice de área foliar e emissividade, em conjunto com constantes e parâmetros físicos para o cálculo das radiações de onda curta e longa, incidentes ou refletidas, foi possível calcular o saldo de radiação na superfície da bacia do Rio Paranaíba, expostos nos mapas 3 e 4 para os dias 31 de julho e 02 de agosto, respectivamente. Na tabela 1, é possível observar a variação sazonal do saldo de radiação à superfície, que apresenta valores mais elevados no mês de dezembro (início do verão), com dias mais longos, temperaturas mais elevadas, além de receber radiação solar em ângulos menos inclinados. 
O saldo de radiação vai ser a principal variável na definição dos fluxos de calor no solo e sensível, que agem diretamente na quantidade de água que retorna à atmosfera por evapotranspiração. Quanto maior o saldo de radiação, maior será a evapotranspiração real. Percebe-se que esses valores são inversamente proporcionais aos valores de albedo, visto que quanto menor a reflexão, maior o saldo de radiação. Consequentemente, os valores de evapotranspiração serão mais elevados.

Tabela 1. Valores médios do saldo final de radiação à superfície $\left(\mathrm{W} / \mathrm{m}^{2}\right)$ por categoria de uso da terra e cobertura vegetal obtidos por tabulação cruzada para a Bacia do Rio Paranaíba (2013).

\begin{tabular}{|c|c|c|c|c|c|c|c|c|c|c|c|c|c|}
\hline USo & $18 / 1$ & $14 / 2$ & $14 / 3$ & $17 / 4$ & $01 / 5$ & $13 / 6$ & $31 / 7$ & $02 / 8$ & $26 / 9$ & $10 / 10$ & $26 / 11$ & $04 / 12$ & $\begin{array}{l}\text { MÉ- } \\
\text { DIA }\end{array}$ \\
\hline $\begin{array}{c}\text { AGRICULTU- } \\
\text { RA }\end{array}$ & $\begin{array}{c}693, \\
6\end{array}$ & $\begin{array}{c}702 \\
4\end{array}$ & $\begin{array}{c}718, \\
7\end{array}$ & $\begin{array}{c}692, \\
8\end{array}$ & 909,2 & 926,4 & $\begin{array}{c}767, \\
8\end{array}$ & $\begin{array}{c}701 \\
1\end{array}$ & 935,0 & 974,0 & 922,5 & 916,0 & 821,6 \\
\hline $\begin{array}{c}\text { AGRICULTU- } \\
\text { RA } \\
\text { IRRIGADA }\end{array}$ & $\begin{array}{c}647, \\
2\end{array}$ & $\begin{array}{c}669 \\
1\end{array}$ & $\begin{array}{c}720 \\
2\end{array}$ & $\begin{array}{c}687 \\
2\end{array}$ & 902,4 & 934,4 & $\begin{array}{c}742, \\
9\end{array}$ & $\begin{array}{c}710 \\
1\end{array}$ & 908,8 & 960,3 & 886,6 & 924,0 & 807,8 \\
\hline ÁGUA & $\begin{array}{c}911, \\
5\end{array}$ & $\begin{array}{c}855 \\
1\end{array}$ & $\begin{array}{c}879 \\
4\end{array}$ & $\begin{array}{c}874, \\
2\end{array}$ & $\begin{array}{c}1116 \\
2\end{array}$ & $\begin{array}{c}1131 \\
6\end{array}$ & $\begin{array}{c}924, \\
1\end{array}$ & $\begin{array}{c}876 \\
0\end{array}$ & $\begin{array}{c}1139 \\
2\end{array}$ & $\begin{array}{c}1173 \\
3\end{array}$ & $\begin{array}{c}1187 \\
0\end{array}$ & $\begin{array}{c}1182 \\
0\end{array}$ & $\begin{array}{c}1020, \\
8\end{array}$ \\
\hline $\begin{array}{c}\text { ÁREA } \\
\text { URBANA }\end{array}$ & $\begin{array}{c}745, \\
0\end{array}$ & $\begin{array}{c}750 \\
0\end{array}$ & $\begin{array}{c}837 \\
5\end{array}$ & $\begin{array}{c}722 \\
6\end{array}$ & 952,3 & 946,6 & $\begin{array}{c}781 \\
3\end{array}$ & $\begin{array}{c}725 \\
2\end{array}$ & 957,8 & 945,2 & 982,8 & $\begin{array}{c}1024 \\
0\end{array}$ & 864,2 \\
\hline CERRADO & $\begin{array}{c}723, \\
2\end{array}$ & $\begin{array}{c}760 \\
6\end{array}$ & $\begin{array}{c}742 \\
8\end{array}$ & $\begin{array}{c}772 \\
2\end{array}$ & 996,6 & 989,6 & $\begin{array}{c}820 \\
4\end{array}$ & $\begin{array}{c}759 \\
3\end{array}$ & $\begin{array}{c}1006, \\
2\end{array}$ & 961,2 & 990,3 & $\begin{array}{c}1063 \\
0\end{array}$ & 882,1 \\
\hline FLORESTA & $\begin{array}{c}746 \\
6\end{array}$ & $\begin{array}{c}789 \\
8\end{array}$ & $\begin{array}{c}745 \\
5\end{array}$ & $\begin{array}{c}756 \\
8\end{array}$ & 981,3 & 996,8 & $\begin{array}{c}819 \\
5\end{array}$ & $\begin{array}{c}766 \\
6\end{array}$ & 996,4 & 995,0 & $\begin{array}{c}1037 \\
3\end{array}$ & $\begin{array}{c}1022 \\
5\end{array}$ & 887,8 \\
\hline PASTAGEM & $\begin{array}{c}742 \\
0\end{array}$ & $\begin{array}{c}766 \\
8\end{array}$ & $\begin{array}{l}724 \\
7\end{array}$ & $\begin{array}{c}746 \\
3\end{array}$ & 960,7 & 967,0 & $\begin{array}{c}785 \\
3\end{array}$ & $\begin{array}{c}719 \\
1\end{array}$ & 959,6 & 972,4 & 970,5 & 994,8 & 859,1 \\
\hline $\begin{array}{c}\text { SILVICULTU- } \\
\text { RA }\end{array}$ & $\begin{array}{c}676 \\
0\end{array}$ & $\begin{array}{c}797 \\
6\end{array}$ & $\begin{array}{c}695 \\
0\end{array}$ & $\begin{array}{c}724 \\
0\end{array}$ & 926,9 & 955,0 & $\begin{array}{c}793 \\
4\end{array}$ & $\begin{array}{c}725 \\
8\end{array}$ & 967,2 & 982,0 & 939,6 & 941,5 & 843,7 \\
\hline $\begin{array}{c}\text { SOLO } \\
\text { DESCOBER- } \\
\text { TO }\end{array}$ & $\begin{array}{c}577 \\
8\end{array}$ & $\begin{array}{c}729 \\
4\end{array}$ & $\begin{array}{c}764, \\
6\end{array}$ & $\begin{array}{c}707 \\
8\end{array}$ & 897,2 & 926,4 & $\begin{array}{c}712 \\
4\end{array}$ & $\begin{array}{c}640 \\
2\end{array}$ & 901,6 & 899,6 & 900,1 & 883,0 & 795,0 \\
\hline
\end{tabular}

Fonte: Imagem MYD09GA - MODIS/AQUA, 2013.

Mapa 3. Saldo de radiação à superfície $\left(\mathrm{W} / \mathrm{m}^{2}\right)$ na bacia do Rio Paranaíba (31/07/2013) 


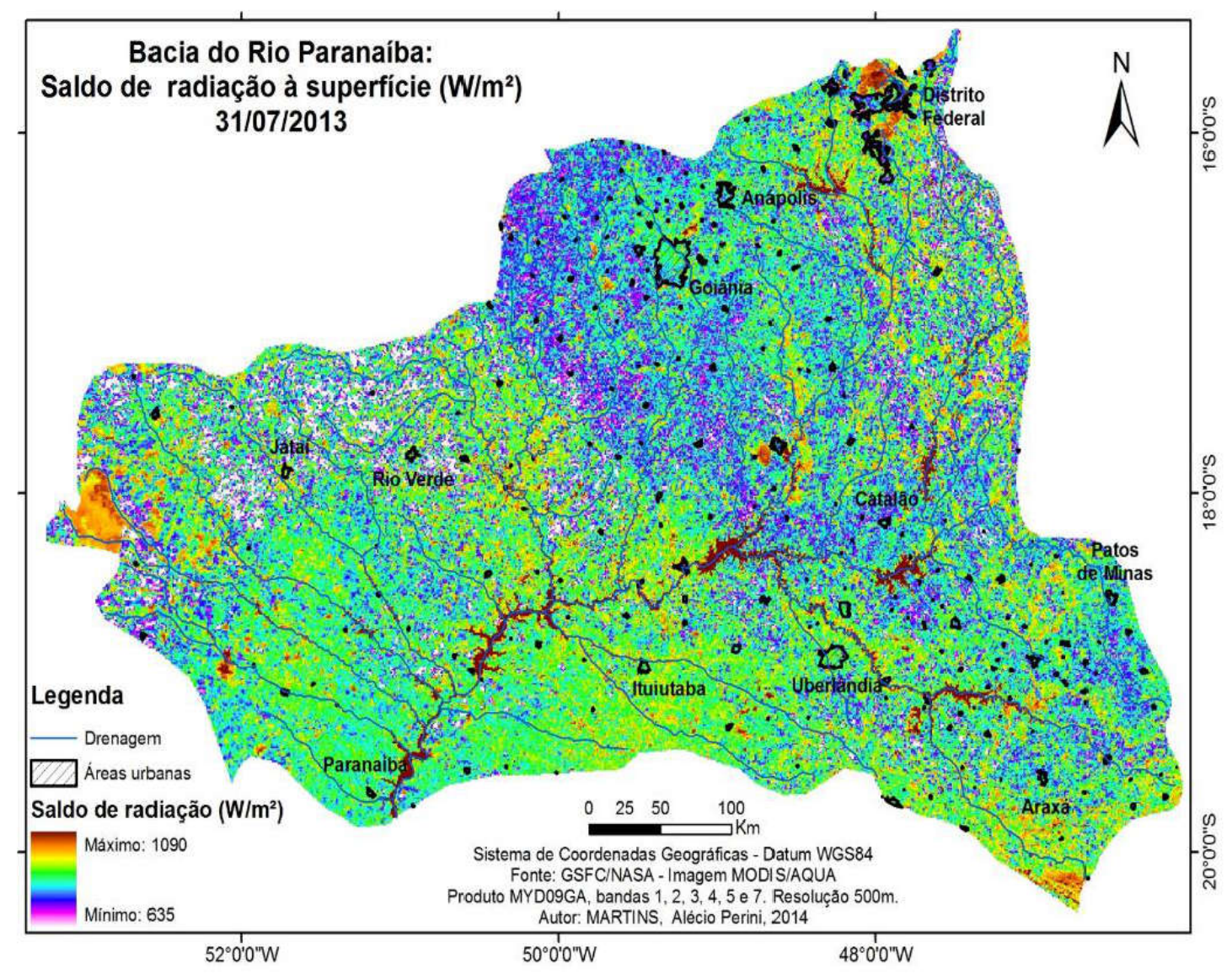

Fonte: Imagem MODIS/AQUA, produto MYD09GA, 2013

Autor: MARTINS, Alécio Perini, 2014.

Mapa 4. Saldo de radiação à superfície $\left(\mathrm{W} / \mathrm{m}^{2}\right)$ na bacia do Rio Paranaíba (02/08/2013) 


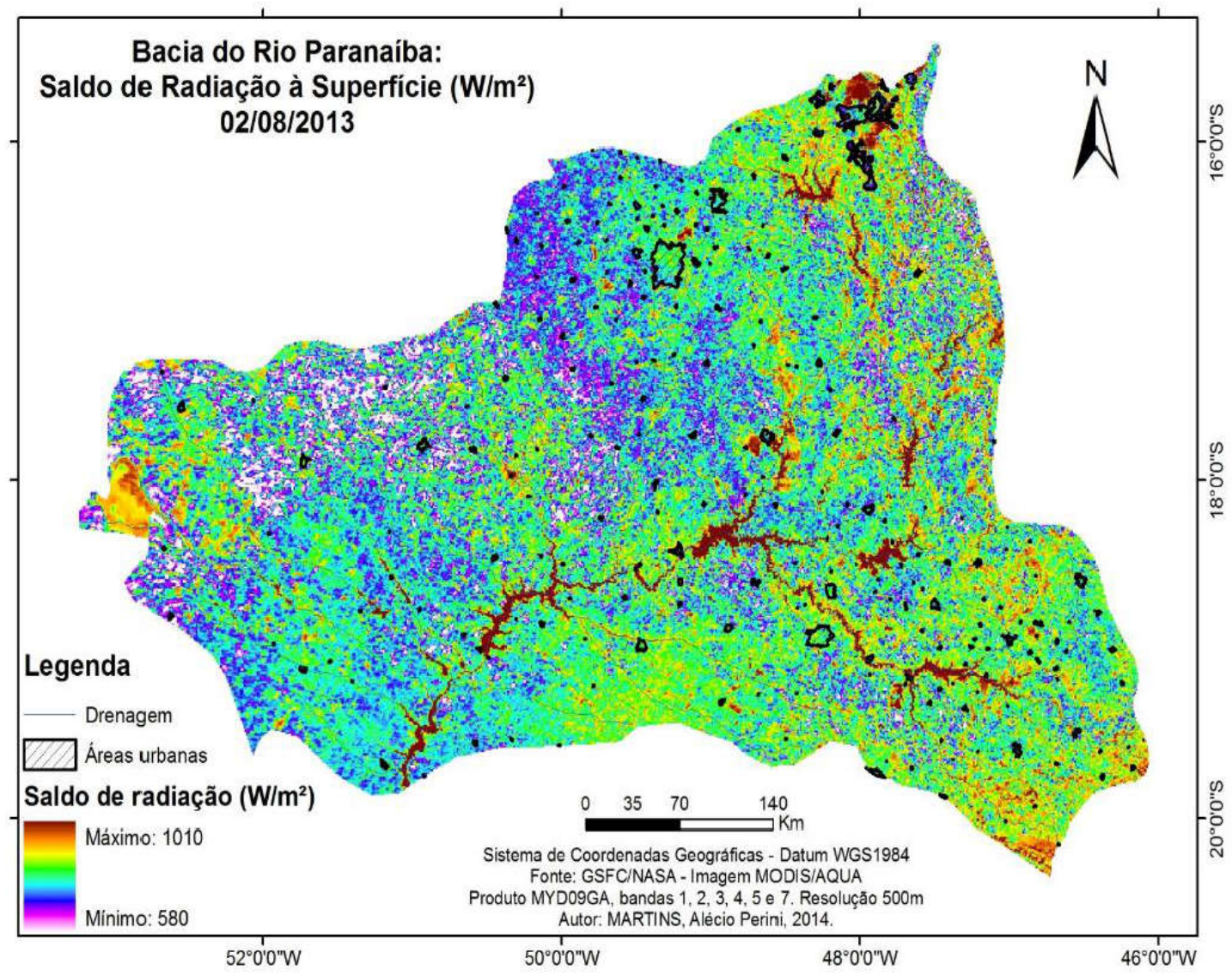

Fonte: Imagem MODIS/AQUA, produto MYD09GA, 2013

Autor: MARTINS, Alécio Perini, 2014.

A relação direta entre albedo e saldo de radiação à superfície é comprovada pelo coeficiente de correlação calculado a partir das médias anuais por categoria de uso da terra, que é de 0,97 . Isso evidencia que, mudanças bruscas nos padrões de uso da terra e cobertura vegetal alteram significativamente os valores de albedo e, consequentemente, do saldo de radiação e no calor latente responsável pela transformação da água do estado líquido para o estado de vapor.

Áreas com vegetação arbórea, incluindo florestas, cerrados e áreas de silvicultura apresentam valores altos de $\mathrm{Rn}$, acima de $800 \mathrm{~W} / \mathrm{m}^{2}$ em 31/07 e de $750 \mathrm{~W} / \mathrm{m}^{2}$ em $02 / 08$. Estas classes, apesar das diferenças nos valores, apresentam limites coincidentes nas duas imagens. Algumas regiões ocupadas com agricultura também apresentam respostas nessa faixa em ambas as imagens.

Os valores médios do saldo de radiação, bem como os valores medianos encontram-se na faixa de 750 a $800 \mathrm{~W} / \mathrm{m}^{2}$ no dia 31 de julho e de 700 a $750 \mathrm{~W} / \mathrm{m}^{2}$ no dia 02 de agosto, coincidindo com áreas ocupadas por pastagens e feições de cerrado, além de áreas ocupadas com agricultura.

Os menores valores registrados, abaixo de $750 \mathrm{~W} / \mathrm{m}^{2}$ no mapa 3 e abaixo de $700 \mathrm{~W} / \mathrm{m}^{2}$ no mapa 4 , correspondem às áreas com solo descoberto e com maior teor de areia, que também foram as áreas que apresentaram maiores valores de albedo e de temperatura de superfície. Nessas áreas, que também incluem alguns pixels de áreas urbanizadas, registram-se picos de fluxo de calor e baixos valores de evapotranspiração, visto que a quantidade de água no solo disponível para esses processos é praticamente zero. 
Nicácio (2008), ao mapear o saldo de radiação à superfície (Rn) para as regiões de Juazeiro e Petrolina, no nordeste brasileiro, para imagens dos meses de outubro e novembro, encontrou valores de $\mathrm{Rn}$ próximos a $731 \mathrm{~W} / \mathrm{m}^{2}$ para corpos hídricos, enquanto que esses valores para a bacia do Rio Paranaíba foram superiores a $1100 \mathrm{~W} / \mathrm{m}^{2}$ para o mesmo período. Ferreira e Meirelles (2011) encontraram valores médios de $825 \mathrm{~W} / \mathrm{m}^{2}$ de $\mathrm{Rn}$ para o dia $06 / 03 / 2010$ para a mesorregião Sul de Goiás, enquanto que a média para o dia 14/03/2013 foi de 759 $\mathrm{W} / \mathrm{m}^{2}$, de acordo com o estudo aqui apresentado. Percebe-se, assim, que os valores de Rn variam muito de acordo com as condições climáticas da região e do dia, visto que todos os estudos citados utilizaram a mesma metodologia e imagens do mesmo sensor, não tendo muito sentido a comparação destes valores com os obtidos em outros estudos.

A partir do saldo de radiação, dos dados de temperatura de superfície, albedo e índice de vegetação, foi possível estimar o fluxo de calor no solo, quando deve-se tomar cuidado com a estimativa desses valores para superfícies cobertas por água. Os resultados obtidos, indicam que o fluxo de calor é maior sobre superfícies líquidas, sendo superiores a $200 \mathrm{~W} / \mathrm{m}^{2}$ para os dias 31/07 e 02/08, valores extremamente altos, mas que se justificam pela época de obtenção das imagens e pelas características climáticas regionais durante o período seco. Ferreira e Meirelles (2011), ao mapearem o fluxo de calor no solo para a mesorregião Sul Goiano, utilizando imagem do mês de março, identificaram valores máximos de $219 \mathrm{~W} / \mathrm{m}^{2}$, enquanto Nicácio (2008) encontrou valores de até $247 \mathrm{~W} / \mathrm{m}^{2}$ para o mês de novembro na região de Petrolina/PE, indicando que os valores mapeados encontram-se dentro do esperado para a região.

\section{CONSIDERAÇÕES FINAIS}

Proposta com o intuito de realizar uma estimativa do saldo de radiação na superfície por meio de imagens de sensoriamento remoto e ferramentas de geoprocessamento, considera-se que a pesquisa atingiu seus objetivos, tanto gerais quanto específicos, com êxito. Pretendia-se comprovar a hipótese de que elementos como albedo, índice de vegetação, temperatura de superfície e saldo de radiação encontram-se intrinsecamente relacionados às categorias de uso da terra e cobertura vegetal, ponto em que também foi obtido êxito.

Comprovou-se que, além das categorias de uso da terra e cobertura vegetal, a ocorrência e distribuição espacial de precipitações, bem como da umidade relativa do ar são elementos fundamentais para compreender essa dinâmica, que mostra padrões diferentes entre os meses de verão e inverno. Também foi comprovado, com a análise dos valores de albedo e índice de vegetação, que alterações nas categorias de uso da terra e cobertura vegetal podem interferir diretamente nos padrões de saldo de radiação que, por sua vez, podem refletir na distribuição regional de chuvas, aumento de temperaturas médias e alterações nas temperaturas máximas e mínimas.

Os procedimentos metodológicos adotados, que foram baseados no SEBAL se mostraram eficientes para mapeamentos e análises em áreas com grande extensão territorial e com poucos dados climáticos disponíveis, visto que utiliza apenas imagens de sensoriamento remoto e dados climatológicos como temperatura média e velocidade dos ventos.

Entre as principais conclusões extraídas do processo de pesquisa e modelagem, destacam-se: 
a) Os principais fatores de influência sobre os resultados das estimativas utilizando o SEBAL é o uso da terra e a ocorrência e distribuição espacial/sazonal de chuvas;

b) O cálculo da temperatura de superfície é primordial ao desempenho do modelo por funcionar como "força motriz" dos processos de evaporação, transpiração e, consequentemente, no balanço de energia. Deve-se tomar cuidado para não calcular a temperatura de brilho, pois os dados precisam de correção de emissividade;

c) A resolução das imagens MODIS/AQUA não são adequadas para análises locais, em escala detalhada, mas apresentam bons resultados para áreas mais extensas, sendo mais indicadas para estudos regionais. Com essas imagens, os melhores resultados são obtidos a partir do trabalho com as bandas 1 e 2 que apresentam resolução espacial de $250 \mathrm{~m}$. Os demais produtos são gerados com resolução espacial de 500 metros.

d) Os valores de albedo de superfície obtidos com o modelo apresentaram índices dentro das faixas citadas na literatura, sendo os valores mínimos registrados sobre corpos d'água e áreas de mata e floresta, estando diretamente relacionados à quantidade de radiação refletida pelos corpos na superfície. Isso leva à conclusão de que, alterações significativas nos padrões de albedo, provocadas por mudanças no uso da terra, podem alterar os padrões de evaporação e transpiração como, por exemplo, a substituição de vegetação arbórea por áreas agrícolas ou pastagens.

e) Quanto ao saldo de radiação à superfície, considera-se que os valores obtidos na modelagem para a Bacia do Rio Paranaíba encontram-se semelhantes aos registrados por outros estudos, como o de Ferreira e Meirelles (2011) que encontraram valores médios de $825 \mathrm{~W} / \mathrm{m}^{2}$ para a região Sul do Estado de Goiás. Deve-se ficar atento ao cálculo da radiação de onda curta incidente na superfície, principalmente na determinação do ângulo de incidência dos raios solares que será responsável pela variação sazonal da radiação.

f) Neste estudo, foram encontrados valores médios superiores a $950 \mathrm{~W} / \mathrm{m}^{2}$ nos meses de setembro, outubro, novembro e dezembro para o saldo de radiação, com duas situações distintas para os valores de evapotranspiração: nos meses de setembro e outubro, sem a ocorrência de chuvas, com valores baixos de evapotranspiração, e nos meses de novembro e dezembro, com os maiores índices estimados, evidenciando a importância da ocorrência de chuvas regulares aos processos de evaporação e transpiração;

g) Os valores baixos de saldo de radiação à superfície registrados em janeiro, que deveria apresentar índices próximos ao registrado em dezembro, devese à cobertura de nuvens em mais de $70 \%$ da área em todas as imagens do mês, que não permitiram uma estimativa mais exata;

Frente aos resultados obtidos com a aplicação do modelo, recomenda-se que sejam utilizadas imagens de diferentes períodos do ano para estimativa e análise das variáveis, bem como o uso de imagens de sensores diferentes para comparação. Imagens Landsat apresentam maior confiabilidade de resultados por apresentarem resolução espacial de 30 metros, reduzindo a matriz de confusão ocasionada pela resolução espacial do sensor MODIS.

Torna-se necessário, também, desenvolver o modelo SEBAL em softwares de distribuição livre, visto que o preço das licenças do ArcGIS pode significar uma barreira para o desenvolvimento de estudos como este. Como encaminhamento, sugere-se tentar desenvolver o modelo em versões mais recentes do SPRING que 
não apresentem problemas de processamento e no Quantum GIS, que tem se mostrado a alternativa gratuita mais viável para substituição do ArcGIS.

\section{REFERÊNCIAS}

AHMAD, M.-UD-DIN, BASTIAANSSEN, W. G. M. Retrieving soil moisture storage in the unsaturated zone using satellite imagery and bi-annual phreatic surface fluctuations. Irrigation and Drainage Systems. v. 17, p. $141-161.2003$.

ALLEN, R. G. Using the FAO-56 dual crop coefficient method over an irrigated region as part of an evapotranspiration intercomparison study. Journal of Hydrology, v. 229, p. 27 - 41. Março de 2000.

ALLEN, R. G. et al. SEBAL (Surface Energy Balance Algorithms for Land) advanced training and users manual - Idaho implementation. Idaho: Idaho University, USA, 2002. 98p.

ANA - AGÊNCIA NACIONAL DE ÁGUAS. Plano de recursos hídricos e do enquadramento dos corpos hídricos superficiais da bacia hidrográfica do Rio Paranaíba. Brasília: ANA, 2013. 312 p.

ANDRADE, R. G. et al. Estimativa do albedo e do saldo de radiação à superfície utilizando imagem MODIS/AQUA na bacia do Rio Ji-Paraná/RO. Campinas, SP: Embrapa Monitoramento por Satélite, 2010. 24p.

ARRAES, C. L.; LAMPARELLI, R. A. C.; ROCHA, J. V. Potencial da TST registrado pelo sensor MODIS em medir temperatura do ar comparado àquelas estimadas pelo ECMWF e por estações meteorológicas. In: SBSR, SIMPÓSIO BRASILEIRO DE SENSORIAMENTO REMOTO, 15, 2011, Curitiba/PR. Anais do XV Simpósio Brasileiro de Sensoriamento Remoto. Curitiba: INPE, 2011. p.0108-0115.

AYENEW, T. Evapotranspiration estimation using thematic mapper spectral satellite data in the Ethiopian rift and adjacent highlands. Journal of Hydrology, v.279, pp. $83-93.2003$.

AYOADE, J. O. Introdução à Climatologia para os Trópicos. $10^{a} \mathrm{Ed}$. Rio de Janeiro: Bertrand do Brasil, 2010.

BASTIAANSSEN, W. G. M., Regionalization of surface flux densities and moisture indicators in composite terrain, Tese (Ph.D.), Wageningem Agricultural University, Wageningen: Netherlands, 273f, 1995.

BASTIAANSSEN, W. G. M. et al. A remote sensing surface energy balance algorithm for land (SEBAL): 2. Validation. Journal of Hydrology, v. $212-213$, pp. $213-229$. 1998.

BASTIAANSSEN, W. G. M. SEBAL-based sensible and latent heat flux in the irrigated Gediz basin, Turkey. Journal of Hydrology, v. 229, pp. 87 - 100. 2000. 
BDMEP - Banco de Dados Meteorológicos para Ensino e Pesquisa. Disponível em http://www.inmet.gov.br/projetos/rede/pesquisal Acesso em 10 abr. 2014.

BEZERRA, B. G. Balanço de energia e evapotranspiração em áreas com diferentes tipos de cobertura de solo no Cariri cearense através do algoritmo SEBAL. Dissertação. UFCG, Campina Grande, PB. 2006.

BEZERRA, B. G; SILVA, B. B.; FERREIRA, N. J. Estimativa da evapotranspiração real diária utilizando-se imagens digitais TM-Landsat5. Revista Brasileira de Meteorologia, vol.23, n.3, p.305-317, 2008.

DEERING, D.W. et al. Measuring "forage production" of grazing units from Landsat MSS data. In: International Symposium on Remoting Sensing of Environment, 10, Ann Arbor, Proceedings. Ann Arbor, MI: ERIM, 1975. v.2, p. 1169-1178.

FERREIRA, A. S.; MEIRELLES, M. S. P. Implementação preliminar do modelo SEBAL para estimativa de evapotranspiração na mesorregião Sul Goiano. In: SBSR, SIMPÓSIO BRASILEIRO DE SENSORIAMENTO REMOTO, 15, 2011, Curitiba/PR. Anais do XV Simpósio Brasileiro de Sensoriamento Remoto. Curitiba: INPE, 2011. p.5576-5583.

GIACOMONI, H. M. Estimativa da evapotranspiração regional por meio de técnicas de sensoriamento remoto integradas a modelos de balanço de energia: aplicação no estado do Rio Grande do Sul. Dissertação (Mestrado em Recursos Hídricos e Saneamento Ambiental) - Universidade Federal do Rio Grande do Sul, 2005. 193p.

GIACOMONI, H.M.; MENDES, C.A.B. Estimativa de Evapotranspiração Regional por meio de Técnicas de Sensoriamento Remoto Integradas a Modelo de Balanço de Energia. Revista Brasileira de Recursos Hídricos, vol 13, n. 4, p. 33-42, out/dez 2008.

GOMES, H. B. Balanço de Radiação e energia em áreas de cultivo de cana-deaçúcar e cerrado no estado de São Paulo mediante imagens orbitais. Tese (Doutorado em Meteorologia) - Universidade Federal de Campina Grande, 2009. $108 p$.

HEMAKUMARA, H. M. et al. Evapotranspiration fluxes over mixed vegetation areas measured from large aperture scintillometer. In Agricultural Water Management, v. 58, p. 109-122. 2003.

KIMURA, R. et al. Evapotranspiration estimation over the river basin of the Loess Plateau of China base on remote sensing, Journal of Arid Environments, v. 68, p. 53-65. 2007.

KONGO, V. M., JEWITT, G. P. W. Preliminary investigation of catchment hydrology in response to agricultural water use innovations: A case study of the Potshini catchement - South Africa. Physics and Chemistry of the Earth, v. 31, p.976-987. 2006. 
LATORRE, M. L.; SHIMABUKURO, Y. E.; ANDERSON, L. O. Produtos para ecossistemas terrestres - MODLAND. In: RUDORFF, B. F. T.; SHIMABUKURO, Y. E.; CEBALLOS, J. C. (Org). O sensor MODIS e suas aplicações ambientais no Brasil. São José dos Campos, SP.: Ed. Parêntese, 2007. p.23-35.

LEITE, M. R.. Sensoriamento remoto aplicado à análise temporal da relação uso da terra/ temperatura e albedo de superfície na bacia do Rio Vieira no norte de Minas Gerais. Dissertação (Mestrado em Geografia) - Instituto de Geografia Universidade Federal de Uberlândia, 2011. 111p.

MENDONÇA, J. C. Estimação da evapotranspiração regional utilizando imagens digitais orbitais na região Norte Fluminense, RJ. Tese. Universidade Estadual do Norte Fluminense, Campos dos Goytacazes, RJ, Brasil. 2007.

MENDONÇA, J. C. et al. Aplicação do algoritmo SEBAL e imagens MODIS para estimativa do fluxo de calor no solo $(G)$ na região Norte Fluminense, RJ, Brasil. In: SBSR, SIMPÓSIO BRASILEIRO DE SENSORIAMENTO REMOTO, 14, 2009, Natal/RN. Anais do XIV Simpósio Brasileiro de Sensoriamento Remoto. Natal: INPE, 2009. p.293-300.

MENDONÇA, J. C. et al. Análise do albedo à superfície a partir de produtos MODIS. In: CBMET, CONGRESSO BRASILEIRO DE METEOROLOGIA, 16, 2010, Belém/PA. Anais do XVI Congresso Brasileiro de Meteorologia. Belém, 2010. p.1-5.

MING, T. C.; LIU, W. T. H. Estimativa de albedo, temperatura e NDVI do estado de São Paulo através de dados AVHRR do satélite NOAA. In: CBM, CONGRESSO BRASILEIRO DE METEOROLOGIA, 11, 2000. Rio de Janeiro/RJ. Anais do XI Congresso Brasileiro de Meteorologia. Rio de Janeiro, 2000. p. 3843-3850.

MODIS. Moderate Resolution Imaging Spectroradiometer. Disponível em <http://modis.gsfc.nasa.gov> Acesso em 15 ago. 2014.

MOREIRA, L. C. J. et. al. Variabilidade local e regional da evapotranspiração estimada pelo algoritmo SEBAL. In: Engenharia Agrícola, Jaboticabal, v30, n06, Nov/dez2010. P.1148-1159.

MOREIRA, M. A. Fundamentos do Sensoriamento Remoto e metodologias de aplicação. 4 ${ }^{a}$ ed. Viçosa, MG: Editora da Universidade Federal de Viçosa, 2011. 422p.

MRTWEB, MODIS Reprojection Tool Web Interface. Enchanced MODIS data discovery and delivery services from the LP DAAC. Disponivel em: <http://www.mrtweb.cr.usgs.gov> Acesso em 15 ago. 2014.

NICÁCIO, R. M. Evapotranspiração real e umidade do solo usando dados de sensores orbitais e a metodologia SEBAL na bacia do Rio SãoFrancisco (Rio de Janeiro). 2008. 337f. Tese (Doutorado em Engenharia Civil) - Programa de PósGraduação em Engenharia Civil, Universidade Federal do Rio de Janeiro, 2008. 
NOVO, E. M. L. M. Sensoriamento Remoto: princípios e aplicações. $3^{\text {a }}$ ed. São Paulo: Ed. Edgard Blücher Ltda, 2008. 363p.

ROSA, R.; SANO, E. E. Uso da Terra e Cobertura Vegetal na Bacia do Rio Paranaíba. CAMPO-TERRITÓRIO: revista de geografia agrária, v.09, p.19, p.32-56. Outubro de 2014.

SOARES, J.V.; BATISTA, G.T.; SHIMABUKURO, Y.E. Histórico e Descrição. In: RUDORFF, B.F.T.; SHIMABUKURO, Y.E.; CEBALLOS, J.C. (Org.). O Sensor MODIS e suas aplicações no Brasil. São José dos Campos, SP.: Ed. Parêntese, 2007. p.1-22.

TASUMI, M. et al. Operational aspects of satellitebased energy balance models for irrigated crops in the semi-arid U.S. Irrigation and Drainage Systems, v. 19, p. 355376. 2005.

TRENTIN, R. et al. Análise comparativa da temperatura de superfície MODIS e temperatura do ar em diferentes situações no estado do Paraná. In: SBSR, SIMPÓSIO BRASILEIRO DE SENSORIAMENTO REMOTO, 15, 2011, Curitiba/PR. Anais do XV Simpósio Brasileiro de Sensoriamento Remoto. Curitiba: INPE, 2011. p.7745-7752.

UDA, P. K. Avaliação da evapotranspiração real da bacia do Alto Rio Negro, região sul brasileira, por meio do modelo SEBAL. 163f. Dissertação (Mestrado em Engenharia Ambiental) - Universidade Federal de Santa Catarina, Florianópolis, 2012. 